\title{
Charge-transfer interaction between antihistamine antiallergic drugs, diphenhydramine, fexofenadine, cetirizine and two $\pi$-acceptors in pharmaceutical forms
}

\author{
Akram M. El-Didamony ${ }^{1} \cdot$ Gehad M. Ramadan ${ }^{2}$ (i)
}

Received: 28 January 2020 / Accepted: 2 March 2020 / Published online: 20 March 2020

(c) Springer Nature Switzerland AG 2020

\begin{abstract}
Two simple and sensitive spectrophotometric techniques have been proposed for the estimation of antihistamine drugs, diphenhydramine hydrochloride (DPH), fexofenadine hydrochloride (FXO) and cetirizine dihydrochloride (CTZ) in pure forms and in their pharmaceutical forms via charge-transfer complex formation with 2,3-dichloro-5,6-dicyano-1,4-benzoquinone (DDQ) and 7,7,8,8-tetracyanoquinodimethane (TCNQ) reagents. Spectrophotometric methods involve the addition a known excess of DDQ or TCNQ reagents to DPH, FXO and CTZ drugs in acetonitrile, followed by the measurement of the absorbance of formed CT complexes at the selected wavelength. Various variables and parameters affecting the reactions were studied and investigated. Beer's law was obeyed in the concentration ranges of 16-144, 12-120, $12-86 \mu \mathrm{g} \mathrm{mL}^{-1}$ and 6-66, 24-216 and 4-68 $\mathrm{g} \mathrm{m} \mathrm{mL}^{-1}$ for DPH, FXO and CTZ drugs using DDQ and TCNQ reagents, respectively, with correlation coefficients not less than 0.9944 . The reaction stoichiometry is found to be 1:1 [drug]: [DDQ or TCNQ]. For the spectrophotometric methods, molar absorptivity, detection and quantification limits, and sandell resistance are also calculated. According to $\mathrm{ICH}$ guidelines, both intra-and inter-day precision and reliability were evaluated. The estimated techniques have been successfully applied in their medicinal forms to the determination of the cited drugs. The finding showed no significant difference between the estimated methods and reported methods, depended on $t$ test and variance ratio. Popular pharmaceutical additives did not interfere.
\end{abstract}

Keywords Spectrophotometric · Antihistamine drugs · DDQ · TCNQ

\section{Introduction}

Diphenhydramine hydrochloride (DPH) (Fig. 1a) (2-(diphenylmethoxy)-N,N-dimethylethanamine) is a chemical mainly used as antihistaminic, antiemetic, sedative, and hypnotic [1]. By blocking the effect of histamine at $\mathrm{H} 1$ receptor sites and decreases their sensitization, $\mathrm{DPH}$ works. This leads to the increase of vascular smooth muscle contraction, so reducing the redness, hyperthermia and edema that occur during an inflammatory reaction. Several techniques were published for the estimation of DPH in pharmaceutical formulations and in biological fluids including: spectrophotometry [2-5], potentiometric [6], high performance liquid chromatography [7, 8], liquid chromatography [9] and capillary electrophoresis $[10,11]$.

Fexofenadine hydrochloride (FXO), ( \pm )-4-[1-hydroxy4-(4-hydroxydiphenyl methyl)-1-piperidinyl]-butyl]-a,adimethyl benzene acetic acid (Fig. 1b) is a non-cardio toxic

Electronic supplementary material The online version of this article (https://doi.org/10.1007/s42452-020-2402-3) contains supplementary material, which is available to authorized users.

Gehad M. Ramadan, dr.jihad2011@yahoo.com | 'Chemistry Department, Faculty of Science, Zagazig University, Zagazig 44519, Egypt. ${ }^{2}$ Pesticide Residues Laboratories, Regional Co-lab, Ministry of Health, Zagazig, Egypt. 
<smiles>CN(C)CCOC(c1ccccc1)c1ccccc1</smiles>

(a)<smiles>CC(C)(C(=O)O)c1ccc(C(O)CCCN2CCC(C(O)(c3ccccc3)c3ccccc3)CC2)cc1</smiles>

(b)

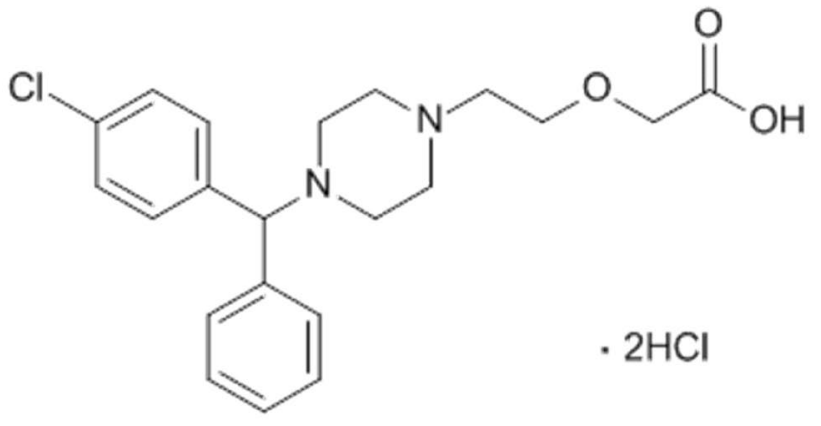

(c)

Fig. 1 Structural forms of the studied drugs: a diphenhydramine, $\mathbf{b}$ fexofenadine and c cetirizine

second-generation histamine $\mathrm{H} 1$-receptor antagonist in piperidine-class drugs used to treat hay fever symptoms. Because it does not cross the blood-brain barrier, sedation or other central nervous system effects don't occur [12]. Fexofenadine has no negative effect on the psychomoto efficiency. The substance has anti-inflammatory characteristics, which presents a modern approach to allergy therapy. For once daily prescription, FXO is suitable because it proved a safer alternative in the treatment of asthma and atopic dermatitis [13] and it is rapidly absorbed with a long duration of action. Several methods for the estimation of fexofenadine hydrochloride in pharmaceutical forms and biological fluids have been published including HPLC [14-19], spectrophotometry [20-24], spectrofluorometry [25], potentiometry [26] and capillary electrophoresis [27].
Cetirizine dihydrochloride (CTZ) (Fig. 1c) named as 2-[2-[4-[(4-chlorophenyl) phenylmethyl] piperazin-1-yl] ethoxy]acetic acid di hydrochloride, is the second generation of histamine $\mathrm{H} 1$ antagonist and it shows high affinity to the histamine $\mathrm{H} 1$ receptors [28]. The efficacy of CTZ is demonstrated by the inhibition of allergic reactions by blocking the activity of histamine in the body and it has been used in the treating of seasonal anaphylactic rhinitis in age more than 2 years for children. Drug analysis is a serious and significant subject in many quality control steps of pharmaceutical applications. A number of analytical methods for quantification of CTZ in bulk and/or pharmaceutical forms are found in the literature. Highperformance liquid chromatography (HPLC) is the most widely used technique $[29,30]$, liquid chromatography [31] and gas chromatography [32]. But, chromatographic methods consume time, large volumes of organic solvents and use expensive HPLC columns. Capillary electrophoresis methods also reported [33, 34], voltammetry [35, 36], potentiometric [37] and spectrophotometric techniques [38].

In this study, two simple, accurate, time saving and sensitive spectrophotometric techniques were developed to assay DPH, FXO and CTZ in pure form and their pharmaceutical preparations. The proposed methods were based on the charge transfer reaction of the cited medicates, as $n$-electron donor, with DDQ and TCNQ, as $\pi$-acceptors. Literature survey did not reveal any of suggested techniques for determination of estimated drugs. Different experimental parameters affecting these reactions are optimized and then Beer's law is carried out.

\section{Experimental}

\subsection{Apparatus}

All the absorption spectral measurements were made using Shimadzu UV-160A, UV-Vis double beam spectrophotometer with scanning speed $400 \mathrm{~nm} \mathrm{~min}^{-1}$ and bandwidth $2 \mathrm{~nm}$, equipped with $10 \mathrm{~mm}$ matched quartz cells.

\subsection{Reagents and solutions}

The reagents of analytical-reagent grade were used, and the solvents of spectroscopic grade were also used. From the Egyptian Pharmaceutical Industries Company (EIP$\mathrm{ICO})$, diphenhydramine hydrochloride (DPH), fexofenadine hydrochloride (FXO) and cetirizine dihydrochloride (CTZ) were getting. The standard solution of used drugs has been prepared as $100 \mathrm{mg}$ of each drug in $100 \mathrm{~mL}$ of distilled water. All solutions were prepared daily. The working solution was prepared as required by suitable dilution 
of the stock solution. A stock solution of $5 \times 10^{-3} \mathrm{M}$ of 2,3-dichloro-5,6-dicyano-1,4-benzoquinone (DDQ) and 7,7,8,8-tetracyanoquinodimethane (TCNQ) were prepared in acetonitrile. DDQ and TCNQ were obtained from Aldrich, Sigma-Aldrich Chemie, Steinheim, Germany.

\subsection{Recommended procedures}

\subsubsection{Preparation of cited drugs base solution}

A $25 \mathrm{~mL}$ of standard solution of $1.0 \mathrm{mg} \mathrm{mL}^{-1}$ of the used drugs was prepared in chloroform and transferred into a $125 \mathrm{~mL}$ separating funnel, followed by $50 \mathrm{~mL}$ of $0.5 \mathrm{M}$ aqueous sodium carbonate solution. These contents were mixed well in the separating funnel and shaken for $2 \mathrm{~min}$. Separation of the two phases were allowed to occur and over anhydrous sodium sulphate, the chloroform layer was let to be dry and evaporated to dryness. Under distilled water, the residue was dissolved and quantitatively transferred to a volumetric flask of $100 \mathrm{~mL}$. To achieve a working concentration, the volume was completed with distilled water to the limit.

\subsubsection{Construction of calibration curves}

According to the optimum conditions specified in Table 1, calibration curves were constructed. This achieved by transfer various aliquots of working standard solutions of the estimated drugs into separate $10 \mathrm{~mL}$ volumetric flasks. For this reaction, $3.0 \mathrm{~mL}$ of $5 \times 10^{-3} \mathrm{M}$ of each acceptor was added, and in the case of DDQ, solution leave to stand at room temperature for the optimum time and in the case of TCNQ, solution was heated on water bath to optimum temperature and heating time. Use acetonitrile solvent to make up to volume and measure the absorbance against the reagent blank at the corresponding $\lambda_{\max }$. The calibration graph was prepared by plotting the measured absorbance versus drug concentration in each case. The unknown concentration was estimated from the calibration graph or calculated from the regression equation.

\subsubsection{Limit of detection, and quantification}

LOD is the lowest amount of analyte in the study or test sample that can be detected. LOQ is the lowest amount of analyte in the study or test sample that can be quantitatively determined by suitable precision and accuracy. By using the following equations designated by $\mathrm{ICH}$ guidelines, LOD and LOQ were determined.

$\mathrm{LOD}=3.3 \mathrm{~s} / \mathrm{k}$
$\mathrm{LOQ}=10 \mathrm{~s} / \mathrm{k}$

where $s$ is the standard deviation of the absorbance measurements and $\mathrm{k}$ is the slope of the related calibration curve [39].

\subsubsection{Accuracy and precision}

To determine accuracy and precision, Intraday and interday analysis of the selected drugs was used. Accuracy was executed to assure the proximity of the test results obtained by the proposed methods to the exact value and precision was executed to ascertain the reproducibility of results for the suggested methods [40]. Samples were prepared in five replicates at three different concentrations within the Beer's law limits and the absorbance of each concentration was recorded in five duplicate $(n=5)$. The results were reported as \%RE and \% RSD.

\subsubsection{Stoichiometric ratio}

Spectrophotometrically, by applying Job's method of continuous variation [41] and mole ratio method [42], the Stoichiometric ratio between the cited drugs and acceptors was estimated. In Job's method of continuous variations of equimolar solutions was employed: $5.0 \times 10^{-2} \mathrm{M}$ for standard solutions of DPH and each of $\pi$-acceptors were used and $5.0 \times 10^{-3} \mathrm{M}$ for standard solutions of $\mathrm{FXO}$ or $\mathrm{CTZ}$ and each of $\pi$-acceptors were used. A group of solutions were set up in Job's system of continuous variations in which the whole volume of drugs and acceptors was kept at $5.0 \mathrm{~mL}$ in whole volume of $10 \mathrm{~mL}$. The reagents under general procedures were mixed in different ratios and completed as directed. In mole ratio method, the experiments were completed by mixing a fixed volume of the selected drugs with different volumes of each reagent separately and completed as explained under prescribed procedure.

\subsubsection{Assay of pharmaceutical preparations}

\section{(i) For tablets}

To calculate the average weight of one tablet of each commercial pharmaceutical form for CTZ or FXO, ten tablets were crushed, powdered, weighed out. An appropriate weight equivalent to $100 \mathrm{mg}$ of the selected drugs was transferred into a $100 \mathrm{~mL}$ measuring flask. Approximately $25 \mathrm{~mL}$ of distilled water was applied and the mixture was shacked in a vigorous way for about $5 \mathrm{~min}$. Then, by using distilled water, the mixture was diluted up to the mark, mixed well and filtered by filter paper. To obtain the working concentrations, a proportion of this solution was 


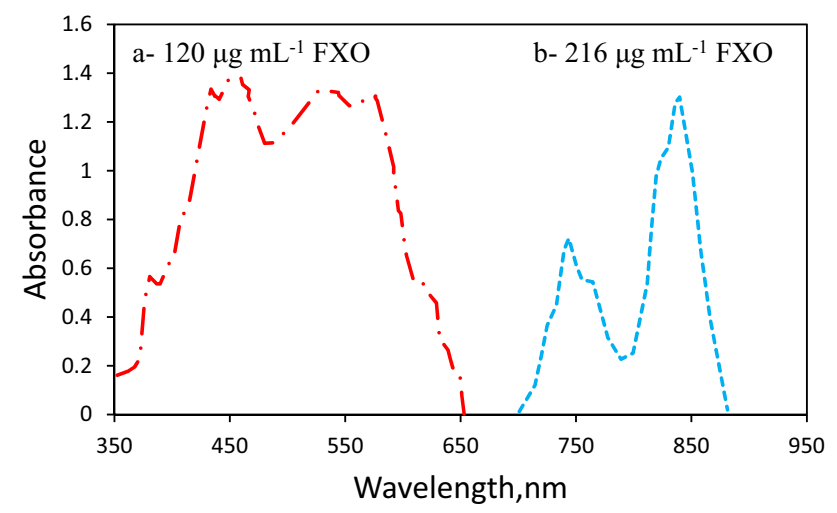

Fig. 2 Absorption spectra of charge-transfer complexes of FXO with $\mathbf{a}$ DDQ and $\mathbf{b}$ TCNQ reagents in acetonitrile diluted appropriately and analyzed as explained under estimated procedure.

\section{(ii) For syrup}

The content of five syrup bottles of each (Diphen syrup, $14 \mathrm{mg} / 5 \mathrm{~mL}$ ) of DPH and (histazine-1 syrup, $5 \mathrm{mg} / 5 \mathrm{~mL}$ ) of CTZ were pooled and mixed. An accurately measured volume of the mixed syrup equal to $100 \mathrm{mg}$ of the selected drugs was transferred quantitatively into a separating funnel and treated as explained under estimated procedure.

\section{Results and discussion}

Due to the interaction of n- electron donor (DPH, FXO and CTZ drugs) with $\pi$-acceptors (DDQ and TCNQ) the formation of charge transfer complex take place, forming a
Fig. 3 Effect of different solvents on color intensity of CT-complexes with DDQ, and TCNQ
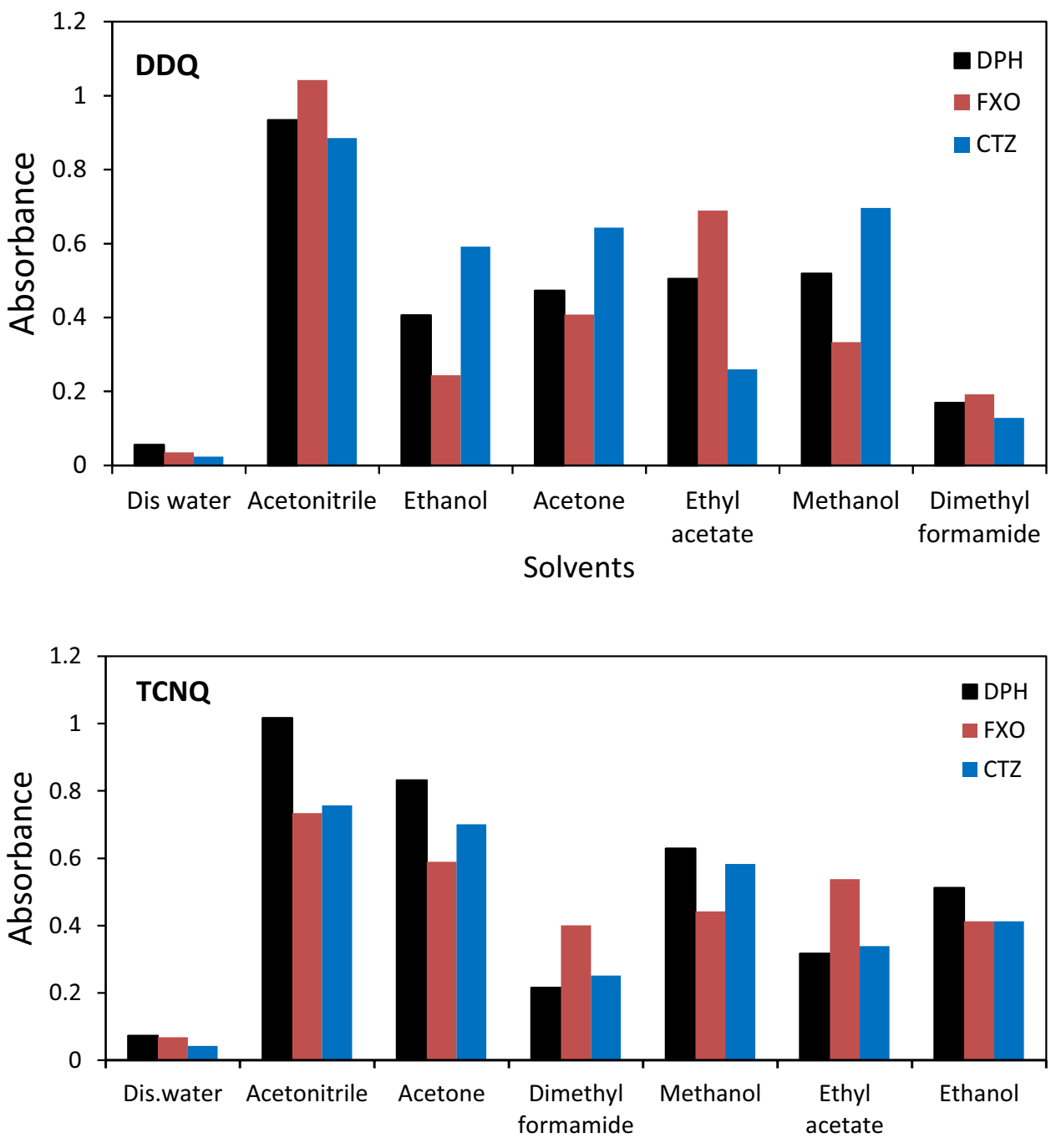

Solvents 
colored charge transfer complexes with low molar absorptivity which created in non-polar solvent. In contrast, a full electron transfer from drugs (D), (n-electron donor), to the acceptor moiety (A) ( $\pi$-acceptors) take place in polar solvents such as acetonitrile with the construct of strong colored radical ions with high molar absorptivity values, according the next equation:

$\mathrm{D}+\mathrm{A} \rightleftarrows{ }_{\text {complex }}^{(\mathrm{D}-\mathrm{A})} \underset{\text { radicals ions }}{\mathrm{D}^{++}+\mathrm{A}^{--}}$
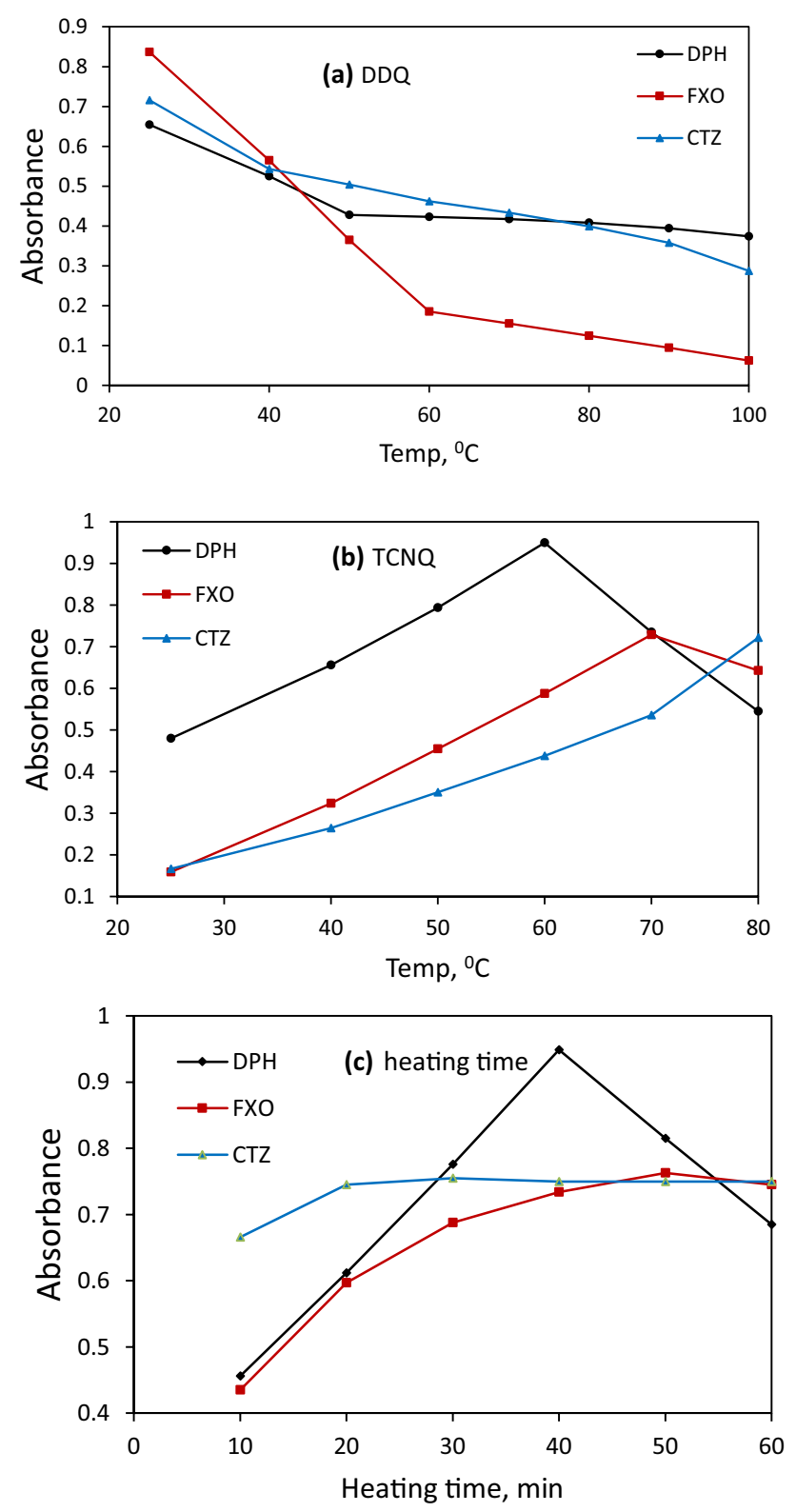

Fig. 4 Effect of temperature $(\mathbf{a}, \mathbf{b})$ and heating time (c) on the absorbance of CT-complexes of DPH, FXO and CTZ with a DDQ $\left(\lambda_{\max }=460 \mathrm{~nm}\right), \mathbf{b}$ TCNQ $\left(\lambda_{\max }=840 \mathrm{~nm}\right)$ reagents in acetonitrile
Acetonitrile (polar solvent) has high degree of ionizing power [43] which confirmed the separation of the donoracceptor complex (D-A). The apparent color complexes have absorption maxima at 460 and $840 \mathrm{~nm}$ for DDQ and TCNQ separately, (Fig. 2).

\subsection{Effect of solvents}

DDQ and TCNQ reagents reacted with DPH, FXO and CTZ drugs in different solvents in order to select the appropriate solvent for $\mathrm{CT}$ complex formation. Water, acetonitrile, acetone, ethanol, ethyl acetate, methanol and dimethylformamide, were these solvents. The ideal solvent for that reaction was acetonitrile with its capacity for DDQ and TCNQ and by high $\varepsilon$ values; it gives the highest yield of the radical anion as indicated in (Fig. 3). This is because it has the high dielectric constant of all solvents examined; which facilitate the dissociation of the original CT complex to radical ions i.e. the dissociation of donor-acceptor complex is enhanced by solvent's high ionizing power [44].
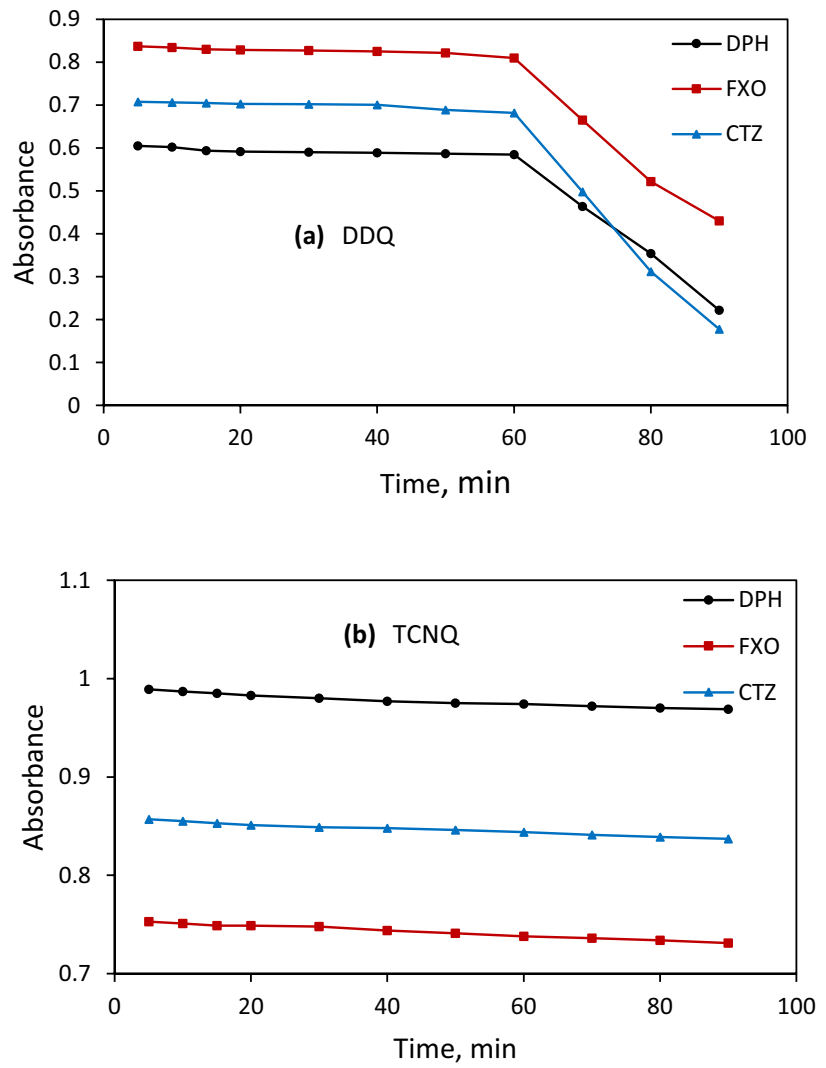

Fig. 5 Effect of time on the absorbance of CT complexes of DPH, FXO and CTZ with $\mathbf{a}$ DDQ and $\mathbf{b}$ TCNQ reagents in acetonitrile 

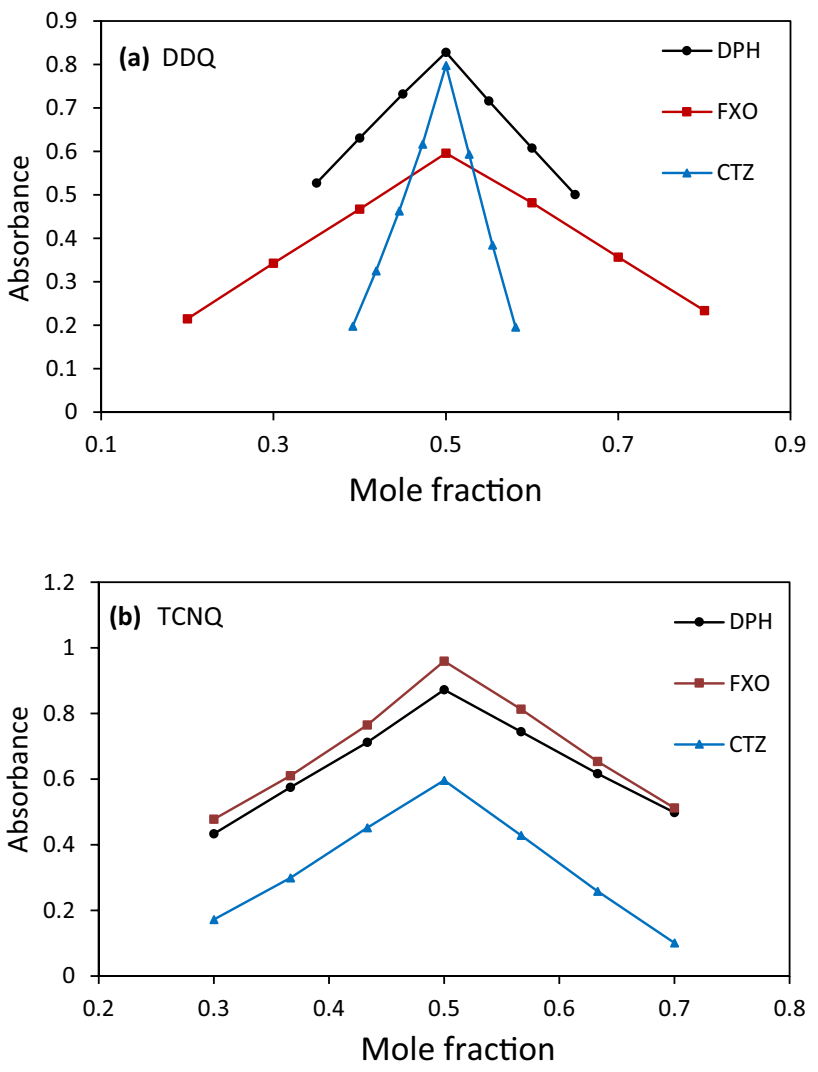

Fig. 6 Continuous variation plot of the reaction products of the studied drugs with: a DDQ and $\mathbf{b}$ TCNQ

\subsection{Effect of reagent concentration}

The drugs were allowed to react with different volumes of the reagents $\left(0.5-4.0 \mathrm{~mL}\right.$ of $5.0 \times 10^{-3} \mathrm{M}$ of both DDQ and TCNQ) to establish optimal concentrations of the reagents for the sensitive and rapid formation of the CT-complexes. In both the cases, maximum and minimum absorbance values were obtained for sample and blank only when $3.0 \mathrm{~mL}$ of the reagent was used, respectively. Thus, $3 \mathrm{~mL}$ was used throughout the analysis as the optimum volume of each reagent in a total volume of $10 \mathrm{~mL}$.

\subsection{Effect of reaction time and temperature}

The optimum time was determined by noticed the color obtained at room temperature $\left(25 \pm 2{ }^{\circ} \mathrm{C}\right)$. Complete color achievement was achieved instantaneously with DDQ (Fig. 4a). Because at room temperature the drug reaction with TCNQ was sluggish, only a pale color emerged and full color production was achieved after $2 \mathrm{~h}$, heating was
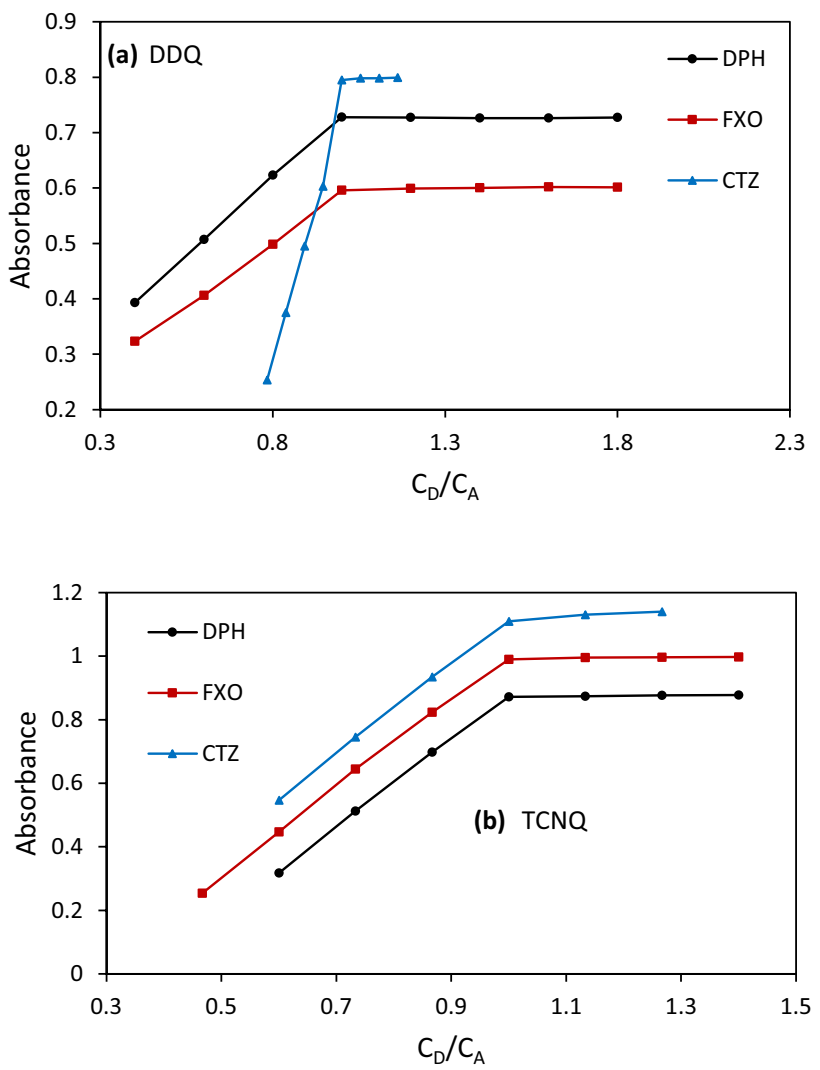

Fig. 7 Mole ratio plot of the reaction products of the studied drugs with: a DDQ and b TCNQ

used. The effect of temperature was studied in the range of $25-80^{\circ} \mathrm{C}$ on the formed complex, (Fig. 4b). The results showed full color development at $60^{\circ} \mathrm{C}$ for $40 \mathrm{~min}, 70^{\circ} \mathrm{C}$ for $50 \mathrm{~min}$ and $80^{\circ} \mathrm{C}$ for $30 \mathrm{~min}$ for DPH, FXO and CTZ, respectively, (Fig. 4C). As shown in Fig. 5, the formed CTcomplexes remained stable at room temperature for $\mathrm{DDQ}$ at least $60 \mathrm{~min}$ and $90 \mathrm{~min}$ for TCNQ.

\subsection{Stability constants of CT-complexes}

By using the Benesi-Hildebrand equation [45], the relative stability constants of the complexes with the two reagents are estimated. The logarithmic stability constants values were 2.93, 2.91, 2.94 and 2.83, 2.89, 2.86 for DDQ and TCNQ complexes, separately.

\subsection{Stoichiometric ratio}

The stoichiometric reaction between the cited drugs and DDQ or TCNQ was determined spectrophotometrically, by 
Scheme 1 Probable reaction mechanisms for FXO with TCNQ as $\pi$-acceptors as example for the proposed methods

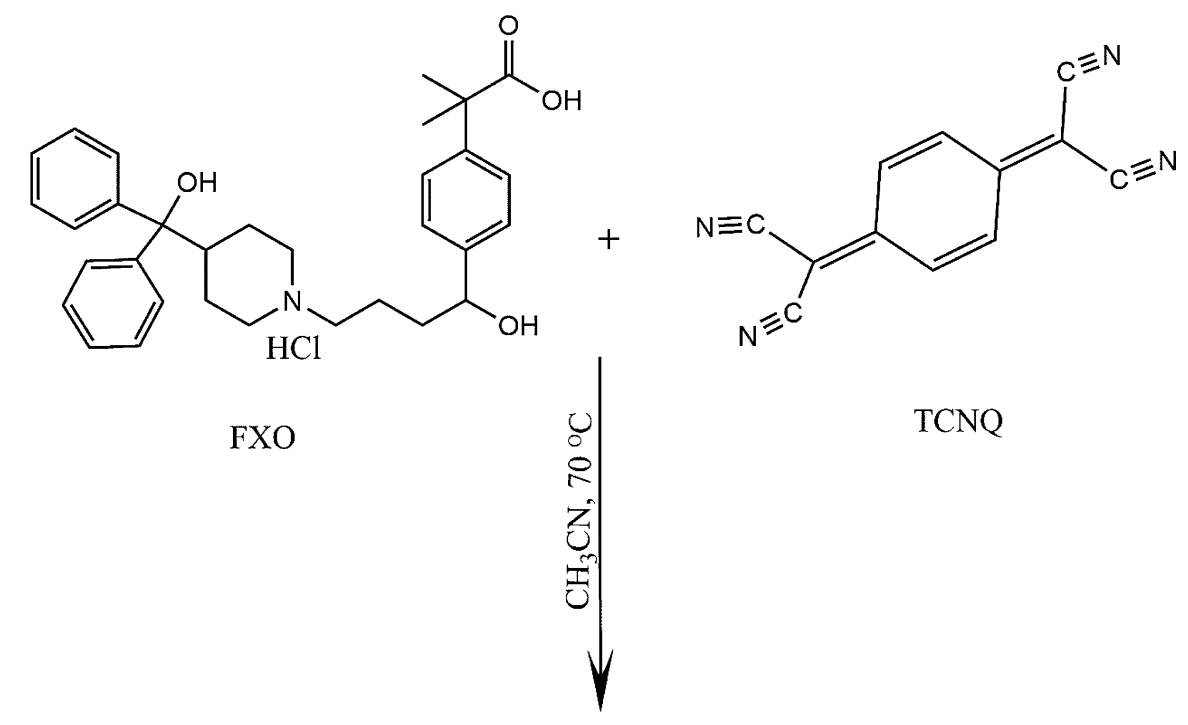<smiles>CC(C)(C(=O)O)c1ccc(C(O)CCC(Cl)=[N+]2CCC(C(O)(c3ccccc3)c3ccccc3)CC2)cc1</smiles>

applying Job's continuous variation and mole ratio methods. The results as in Figs. 6, 7 showed that, the relation between the examined drugs and each one of $\pi$-acceptors was found to be 1:1. Although the drug has two nitrogen atoms, only one nitrogen atom will be used in the formation of CT complexes. Depended on that, a possible path of reaction is proposed and shown in Schemes 1 and 2 for the formation of the CT complex.

\subsection{Validation of the proposed method}

The methods developed are confirmed in accordance with linearity, accuracy and precision, detection limit and quantification and according to the rules set by the International Conference on Harmonization ICH Q2 (R1) [46].

\subsubsection{Linearity, detection, and quantitation limits}

The relationship between absorbance and concentration was quite linear in the concentration ranges given in Table 1 based on the estimated experimental parameters (Fig. 8). Table 1 summarizes the values of intercept (a), slope (b), correlation coefficient ( $r$ ), molar absorptivity (e), and sandell sensitivity. The detection limit (LOD) and quantification limit (LOQ) were calculated as listed in Table 1.

\subsubsection{Accuracy and precision}

The accuracy and precision of the proposed spectrophotometric method were tested by performing five times analyses on drug solutions for pure DPH, FXO and CTZ at three 
Scheme 2 Probable reaction mechanisms for FXO with DDQ as $\pi$-acceptors as example for the proposed methods<smiles>CC(C)(C(=O)O)c1ccc(C(O)CCCN2CCC(C(O)(c3ccccc3)c3ccccc3)CC2)cc1</smiles><smiles>CC(C)(C(=O)O)c1ccc(C(O)CC[N+](Cl)(Cl)CCC2(Cl)C(=O)C(C#N)=C(C#N)C(=O)C2(Cl)Cl)cc1</smiles> 

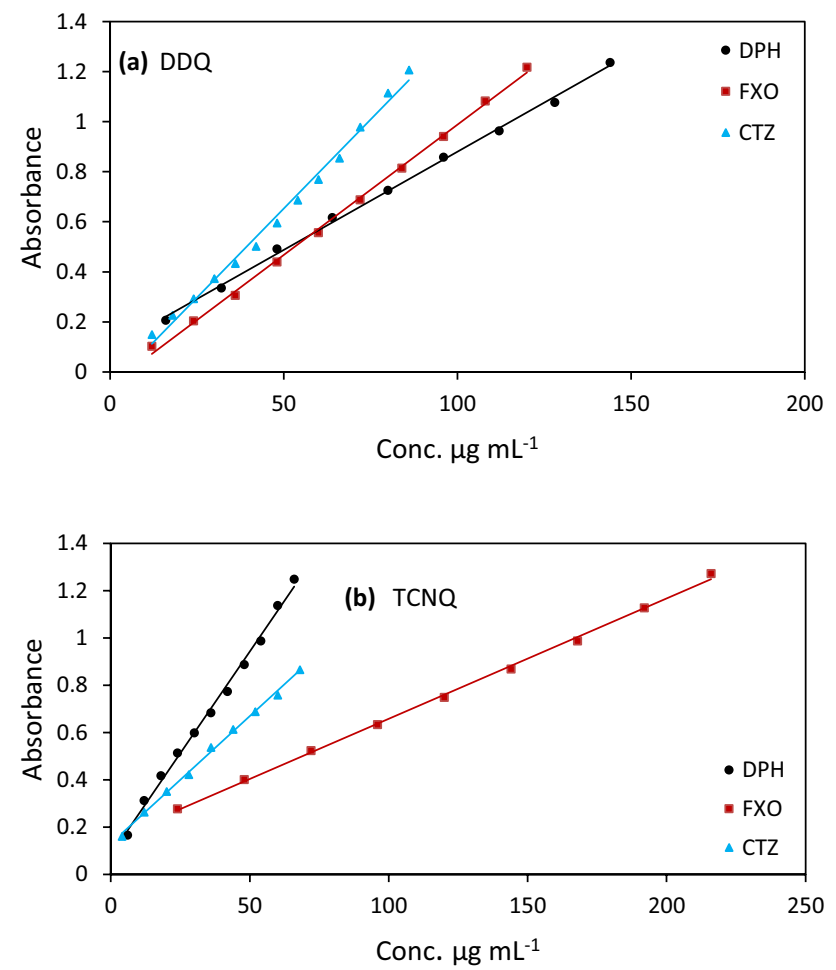

Fig. 8 Calibration graphs for determination of the studied drugs with a DDQ and $\mathbf{b}$ TCNQ different concentration levels within the working range Table 2 calculated the percentage relative standard deviation (RSD \%) as accuracy and relative error (RE) as accuracy of the estimated spectrophotometric methods. The test of intra- and inter-day accuracy and precision indicate that the estimated techniques have good repeatability and reproducibility as shown in Table 2.

\subsubsection{Analytical application}

The estimated methods have been applied to pharmaceutical form which commercially available to quantify the cited drugs. The results obtained were compared with those by reference methods [5, 23, 24]. The statistical analysis of the results detected no significant difference in the performance of the proposed methods and the reported methods by the Student's $t$ value and variance ratio $F$ value. The results of this study are given in Tables 3 and 4.

Table 1 Quantification parameters for the formed CT-complexes

\begin{tabular}{|c|c|c|c|c|c|c|}
\hline \multirow[t]{2}{*}{ Parameters } & \multicolumn{3}{|l|}{ DDQ } & \multicolumn{3}{|l|}{ TCNQ } \\
\hline & DPH & FXO & $\mathrm{CTZ}$ & DPH & FXO & $\mathrm{CTZ}$ \\
\hline$\lambda_{\max }(\mathrm{nm})$ & 460 & 460 & 460 & 840 & 840 & 840 \\
\hline $\operatorname{Temp}\left({ }^{\circ} \mathrm{C}\right)$ & $25 \pm 2$ & $25 \pm 2$ & $25 \pm 2$ & 60 & 70 & 80 \\
\hline Heating time (min) & 5 & 5 & 5 & 40 & 50 & 30 \\
\hline Beer's law limit $\left(\mu \mathrm{g} \mathrm{m} \mathrm{L}^{-1}\right)$ & $16-144$ & $12-120$ & $12-86$ & $6-66$ & $24-216$ & $4-68$ \\
\hline Molar absorptivity $\left(\mathrm{L} \mathrm{mol}^{-1} \mathrm{~cm}^{-1} \times 10^{3}\right)$ & 2.50 & 6.18 & 7.28 & 5.52 & 3.17 & 5.88 \\
\hline Sandell's sensitivity $\left(\mathrm{ng} \mathrm{cm}^{-2}\right)$ & 116.60 & 87.02 & 63.42 & 52.84 & 109.81 & 78.52 \\
\hline Correlation coefficient $(r)$ & 0.9987 & 0.9986 & 0.9994 & 0.9944 & 0.9998 & 0.9983 \\
\hline Linear regression equation* & $A=a+b C$ & & & & & \\
\hline Intercept (a) & 0.08 & 0.02 & 0.01 & 0.09 & 0.16 & 0.12 \\
\hline Slope (b) & $8.14 \times 10^{-3}$ & $8.61 \times 10^{-3}$ & $1.17 \times 10^{-4}$ & $1.68 \times 10^{-4}$ & $4.90 \times 10^{-3}$ & $1.12 \times 10^{-4}$ \\
\hline$S_{y / x}$ & $1.35 \times 10^{-4}$ & $1.30 \times 10^{-4}$ & $5.21 \times 10^{-3}$ & $2.24 \times 10^{-4}$ & $4.29 \times 10^{-3}$ & $1.09 \times 10^{-4}$ \\
\hline S.D. of slope $\left(\mathrm{S}_{\mathrm{b}}\right)$ & $2.03 \times 10^{-4}$ & $2.59 \times 10^{-4}$ & $2.07 \times 10^{-4}$ & $8.93 \times 10^{-4}$ & $4.28 \times 10^{-4}$ & $3.28 \times 10^{-4}$ \\
\hline S.D. of intercept $\left(S_{a}\right)$ & $4.64 \times 10^{-3}$ & $4.45 \times 10^{-3}$ & $2.29 \times 10^{-3}$ & $7.66 \times 10^{-3}$ & $1.47 \times 10^{-3}$ & $3.21 \times 10^{-3}$ \\
\hline $\operatorname{LOD}\left(\mu \mathrm{g} \mathrm{mL}^{-1}\right)$ & 1.08 & 1.03 & 0.76 & 0.56 & 1.93 & 0.84 \\
\hline $\mathrm{LOQ}\left(\mu \mathrm{g} \mathrm{mL} \mathrm{L}^{-1}\right)$ & 3.30 & 3.12 & 2.29 & 1.70 & 5.86 & 2.55 \\
\hline Log stability constant $(\mathrm{K})\left(\mathrm{L} \mathrm{mol}^{-1}\right)$ & 2.93 & 2.91 & 2.94 & 2.83 & 2.89 & 2.86 \\
\hline Standard free energy $(\Delta \mathrm{G})\left(\mathrm{k} J \mathrm{~mol}^{-1}\right)$ & $-2.00 \times 10^{3}$ & $-3.97 \times 10^{3}$ & $-2.02 \times 10^{3}$ & $-4.30 \times 10^{3}$ & $-4.57 \times 10^{3}$ & $-4.06 \times 10^{3}$ \\
\hline
\end{tabular}

${ }^{a} A=a+b C$, where $A$ is the absorbance, $C$ is the concentration in $\mu \mathrm{g} \mathrm{mL}^{-1}$, $a$ is an intercept, $b$ is a slope

${ }^{b}$ Limit of quantification and detection is calculated according to the $\mathrm{ICH}$ guidelines 
Table 2 Evaluation of intra-day and inter-day accuracy and precision

\begin{tabular}{|c|c|c|c|c|c|c|c|c|}
\hline Drugs & $\begin{array}{l}\text { Drug taken } \\
\left(\mu \mathrm{gL}^{-1}\right) \\
\text { DDQ }\end{array}$ & Recovery $^{\mathrm{a}}(\%)$ & RSD (\%) & RE (\%) & $\begin{array}{l}\text { Drug taken } \\
\left(\mu \mathrm{gL}^{-1}\right) \\
\text { TCNQ }\end{array}$ & Recovery $^{\mathrm{a}}(\%)$ & RSD (\%) & RE (\%) \\
\hline \multicolumn{9}{|l|}{ Intra } \\
\hline \multirow[t]{3}{*}{$\mathrm{DPH}$} & 32 & 99.99 & 0.63 & $-3.12 \times 10^{-3}$ & 12 & 99.99 & 0.69 & $-4.33 \times 10^{-3}$ \\
\hline & 32 & 99.99 & 0.29 & $-1.56 \times 10^{-3}$ & 30 & 99.99 & 0.25 & $-3.33 \times 10^{-3}$ \\
\hline & 64 & 99.99 & 0.18 & $-1.04 \times 10^{-3}$ & 42 & 99.99 & 0.21 & $-2.38 \times 10^{-3}$ \\
\hline \multirow[t]{3}{*}{ FXO } & 96 & 99.99 & 1.31 & $-4.17 \times 10^{-3}$ & 24 & 100.00 & 0.32 & Zero \\
\hline & 24 & 99.99 & 0.26 & $-2.08 \times 10^{-3}$ & 72 & 99.99 & 0.44 & $-1.39 \times 10^{-3}$ \\
\hline & 48 & 99.99 & 0.24 & $-1.39 \times 10^{-4}$ & 120 & 99.99 & 0.17 & $-7.33 \times 10^{-3}$ \\
\hline \multirow[t]{3}{*}{ CTZ } & 72 & 99.99 & 0.80 & $-5.56 \times 10^{-3}$ & 12 & 99.99 & 0.53 & $-5.33 \times 10^{-3}$ \\
\hline & 18 & 99.99 & 0.48 & $-3.33 \times 10^{-3}$ & 28 & 99.99 & 0.69 & $-3.57 \times 10^{-3}$ \\
\hline & 30 & 99.99 & 0.32 & $-2.08 \times 10^{-3}$ & 52 & 99.99 & 0.17 & $-1.92 \times 10^{-3}$ \\
\hline \multicolumn{9}{|l|}{ Inter } \\
\hline \multirow[t]{3}{*}{$\mathrm{DPH}$} & 32 & 99.99 & 0.39 & $-3.12 \times 10^{-3}$ & 12 & 99.99 & 0.53 & $-3.11 \times 10^{-3}$ \\
\hline & 64 & 99.99 & 0.21 & $-1.56 \times 10^{-3}$ & 30 & 99.99 & 0.30 & $-4.13 \times 10^{-3}$ \\
\hline & 96 & 100.00 & 0.13 & Zero & 42 & 99.99 & 0.15 & $-1.98 \times 10^{-3}$ \\
\hline \multirow[t]{3}{*}{ FXO } & 24 & 100.00 & 0.72 & Zero & 24 & 99.99 & 0.41 & $-4.17 \times 10^{-3}$ \\
\hline & 48 & 99.99 & 0.26 & $-2.08 \times 10^{-3}$ & 72 & 99.99 & 0.28 & $-2.13 \times 10^{-3}$ \\
\hline & 72 & 99.99 & 0.22 & $-1.39 \times 10^{-3}$ & 120 & 99.99 & 0.38 & $-5.24 \times 10^{-3}$ \\
\hline \multirow[t]{3}{*}{ CTZ } & 18 & 99.99 & 0.69 & $-5.56 \times 10^{-3}$ & 12 & 99.99 & 0.43 & $-4.67 \times 10^{-3}$ \\
\hline & 30 & 99.99 & 0.48 & $-3.33 \times 10^{-3}$ & 28 & 99.99 & 0.35 & $-2.87 \times 10^{-3}$ \\
\hline & 48 & 99.99 & 0.20 & $-2.08 \times 10^{-3}$ & 52 & 99.99 & 0.19 & $-2.14 \times 10^{-3}$ \\
\hline
\end{tabular}

${ }^{\mathrm{a}}$ Mean value of five determinations, \%RE: percent relative error, \%RSD: relative standard deviation 
Table 3 Recovery of the studied drugs in formulations using DDQ

\begin{tabular}{|c|c|c|c|c|c|c|}
\hline Drug formulations & $\begin{array}{l}\text { Drug taken } \\
\left(\mu \mathrm{mL}^{-1}\right)\end{array}$ & $\begin{array}{l}\text { Drug found } \\
\left(\mu \mathrm{g} \mathrm{mL} L^{-1}\right)\end{array}$ & Recovery $^{\mathrm{a}}(\%)$ & $\mathrm{RSD}^{\mathrm{b}}(\%)$ & $\operatorname{RE}^{\mathrm{C}}(\%)$ & Reported methods \\
\hline \multirow{3}{*}{$\begin{array}{l}\text { Diphensyrup } \\
14 \mathrm{mg} / 5 \mathrm{~mL}\end{array}$} & 32 & 32 & 100.00 & 0.38 & Zero & \\
\hline & 64 & 63.99 & 99.99 & 0.25 & $-1.56 \times 10^{-3}$ & \\
\hline & 96 & 95.99 & 99.99 & 0.13 & $-1.04 \times 10^{-3}$ & \\
\hline Recovery \pm RSD & & & $99.99 \pm 0.25$ & & & $100.00 \pm 0.83$ \\
\hline t test & & & 0.50 & & & \\
\hline F test & & & 0.68 & & & \\
\hline \multirow[t]{3}{*}{ Allerfen $180 \mathrm{mg} /$ tablet $^{\mathrm{e}}$} & 24 & 24 & 100.00 & 1.05 & Zero & \\
\hline & 48 & 47.99 & 99.99 & 0.65 & $-2.08 \times 10^{-3}$ & \\
\hline & 72 & 72 & 100.00 & 0.17 & Zero & \\
\hline Recovery \pm RSD & & & $99.99 \pm 0.62$ & & & $100.00 \pm 2.31$ \\
\hline t test & & & 0.39 & & & \\
\hline$F$ test & & & 0.68 & & & \\
\hline \multirow[t]{3}{*}{ Zyrtec $10 \mathrm{mg} /$ tablet $^{f}$} & 18 & 17.99 & 99.99 & 0.49 & $-5.56 \times 10^{-3}$ & \\
\hline & 30 & 29.99 & 99.99 & 0.33 & $-3.33 \times 10^{-3}$ & \\
\hline & 48 & 48.01 & 100.02 & 0.23 & $15.62 \times 10^{-3}$ & \\
\hline Recovery $\pm \mathrm{RSD}$ & & & $100.0 \pm 0.35$ & & & $100.01 \pm 0.84$ \\
\hline t test & & & 0.39 & & & \\
\hline F test & & & 0.90 & & & \\
\hline \multirow[t]{3}{*}{ Histazine-1 syrup $5 \mathrm{mg} / 5 \mathrm{~mL}^{\mathrm{g}}$} & 18 & 17.99 & 99.99 & 0.47 & $-5.56 \times 10^{-3}$ & \\
\hline & 30 & 29.99 & 99.99 & 0.34 & $-3.33 \times 10^{-3}$ & \\
\hline & 48 & 47.99 & 99.99 & 0.22 & $-2.08 \times 10^{-3}$ & \\
\hline Recovery \pm RSD & & & $99.99 \pm 0.34$ & & & $100.01 \pm 0.84$ \\
\hline t test & & & 0.40 & & & \\
\hline$F$ test & & & 0.93 & & & \\
\hline
\end{tabular}

${ }^{a}$ Mean value of five determinations

${ }^{\mathrm{b}} R S D$ relative standard deviation

${ }^{c} R E$ relative error

${ }^{d}$ Produced by Egyptian Int. Pharmaceutical Industries Co. (EIPICO) 10th of Ramadan, Egypt

eProduced byAmoun Pharmaceutical Co El Obour city, Cairo, Egypt

fProduced by Glaxosmithkline, Cairo, under license from: UCB, Belgium

${ }^{9}$ Produced by Amriya for pharmaceutical industries Alex., Egypt 
Table 4 Recovery of the studied drugs in formulations using TCNQ

\begin{tabular}{|c|c|c|c|c|c|c|}
\hline Drug formulations & $\begin{array}{l}\text { Drug taken } \\
\left(\mu \mathrm{g} \mathrm{mL} \mathrm{m}^{-1}\right)\end{array}$ & $\begin{array}{l}\text { Drug found } \\
\left(\mu \mathrm{gL}^{-1}\right)\end{array}$ & Recovery $^{\mathrm{a}}(\%)$ & $\mathrm{RSD}^{\mathrm{b}}(\%)$ & $\mathrm{RE}^{\mathrm{C}}(\%)$ & Reported methods \\
\hline \multirow{3}{*}{$\begin{array}{l}\text { Diphensyrup } \\
14 \mathrm{mg} / 5 \mathrm{~mL}\end{array}$} & 12 & 12 & 100.00 & 0.66 & Zero & \\
\hline & 30 & 29.99 & 99.99 & 0.43 & $-3.33 \times 10^{-3}$ & \\
\hline & 42 & 41.99 & 99.99 & 0.22 & $-2.38 \times 10^{-3}$ & \\
\hline Recovery \pm RSD & & & $99.99 \pm 0.44$ & & & $100.00 \pm 0.83$ \\
\hline t test & & & 0.43 & & & \\
\hline F test & & & 0.54 & & & \\
\hline \multirow[t]{3}{*}{ Allerfen 180 mg/tablet ${ }^{e}$} & 24 & 23.99 & 99.99 & 0.50 & $-4.17 \times 10^{-3}$ & \\
\hline & 72 & 72 & 100.00 & 0.44 & Zero & \\
\hline & 120 & 119.99 & 99.99 & 2.50 & $-8.33 \times 10^{-4}$ & \\
\hline Recovery $\pm \mathrm{RSD}$ & & & $99.99 \pm 1.15$ & & & $100.00 \pm 2.31$ \\
\hline $\mathrm{t}$ test & & & 0.48 & & & \\
\hline F test & & & 0.71 & & & \\
\hline \multirow[t]{3}{*}{ Zyrtec 10 mg/tablet ${ }^{\mathrm{f}}$} & 12 & 11.99 & 99.99 & 0.55 & $-8.33 \times 10^{-3}$ & \\
\hline & 28 & 28 & 100.00 & 0.26 & Zero & \\
\hline & 52 & 51.99 & 99.99 & 0.24 & $-1.92 \times 10^{-3}$ & \\
\hline Recovery $\pm \mathrm{RSD}$ & & & $99.99 \pm 0.35$ & & & $100.01 \pm 0.84$ \\
\hline t test & & & 0.44 & & & \\
\hline F test & & & 0.86 & & & \\
\hline \multirow[t]{3}{*}{ Histazine- 1 syrup 5 mg/5 mL } & 12 & 11.99 & 99.99 & 0.41 & $-8.33 \times 10^{-3}$ & \\
\hline & 28 & 27.99 & 99.99 & 0.38 & $-3.57 \times 10^{-3}$ & \\
\hline & 52 & 51.99 & 99.99 & 0.19 & $-1.92 \times 10^{-3}$ & \\
\hline Recovery $\pm \mathrm{RSD}$ & & & $99.99 \pm 0.33$ & & & $100.01 \pm 0.84$ \\
\hline t test & & & 0.44 & & & \\
\hline F test & & & 0.90 & & & \\
\hline
\end{tabular}

${ }^{a}$ Mean value of five determinations

${ }^{\mathrm{b}} R S D$ relative standard deviation

${ }^{c} R E$ relative error

dProduced by Egyptian Int. Pharmaceutical Industries Co. (EIPICO) 10th of Ramadan, Egypt

eProduced byAmoun Pharmaceutical Co El Obour city, Cairo, Egypt

${ }^{f}$ Produced by Glaxosmithkline, Cairo, under license from: UCB, Belgium

${ }^{9}$ Produced by Amriya for pharmaceutical industries Alex., Egypt

\section{Conclusions}

1. This study explained the development and validation of spectrophotometric analysis depended on their CT reaction with $D D Q$ and TCNQ reagents for the estimation of DPH, FXO and CTZ drugs.

2. These methods were simple, economical, accurate, sensitive, time-saving and environmental friendly which applied in acetonitrile to form CT complexes.

3. The main advantage of the estimated methods is their availability in pure form and formulations for routine quality control of the drug without fear of contamination caused by the additives supposed to be present in formulations.
Acknowledgements The authors would like to express their gratitude to the researchers who have been referenced to successfully present this study. This research work is based on the personal contribution of the authors without any grant from any specific funding agency.

\section{Compliance with ethical standards}

Conflict of interest The authors have declared no conflict of interest.

\section{References}

1. Reynolds JEF (1993) Martindale the extra pharmacopoeia, 30th edn. Pharmaceutical press, London, p 937

2. Mirzaev Kh, Gamzaeva U (2018) A molybdenum (VI)-galleindiphenhydramine ion associate and its application to the extraction-photometric determination of diphenhydramine. J Anal Chem 73:661-666 
3. Al Bratty M (2016) Visible spectrophotometric determination of chlorpheniramine maleate and diphenhydramine hydrochloride in raw and dosage form using potassium permanganate. Orient J Chem 32:885-894

4. Ulu ST, Elmali FT (2010) Spectrophotometric method for the determination, validation, spectroscopic and thermal analysis of diphenhydramine in pharmaceutical preparation. Spectrochim Acta A 77:324-329

5. El-Didamony AM, Moustafa MA (2010) Spectrophotometric determination of diphenhydramine hydrochloride in pharmaceutical preparations and biological fluids via ion-pair formation. Arab J Chem 3:265-270

6. Frag EYZ, Mohamed GG, El-Sayed WG (2011) Potentiometric determination of antihistaminic diphenhydramine hydrochloride in pharmaceutical preparations and biological fluids using screen-printed electrode. Bioelectrochem 82:79-86

7. Bhole RP, Shinde SS, Chitlange SS, Wankhede B (2015) A highperformance thin layer chromatography (HPTLC) method for simultaneous determination of diphenhydramine hydrochloride and naproxen sodium in tablets. Anal Chem Insights 10:47-51

8. Donmez OA, Asci B, Bozdogan A, Sungur S (2011) Simultaneous determination of potassium guaiacolsulfonate, guaifenesin, diphenhydramine $\mathrm{HCl}$ and carbetapentane citrate in syrups by using HPLC-DAD coupled with partial least squares multivariate calibration. Talanta 83:1601-1605

9. Njuguna NM, Abuga KO, Kamau FN, Thoithi GN (2017) A liquid chromatography method for simultaneous determination of diphenhydramine, promethazine, chlorpheniramine and ephedrine in cold-cough syrups. Pharm Chem J 51:153-158

10. Costa BM, Marra MC, Oliveira TC, Munoz RAA, Batista AD, Do Lago CL, Richter EM (2018) Ultrafast capillary electrophoresis method for the simultaneous determination of ammonium and diphenhydramine in pharmaceutical samples. J Sep Sci 41:2865-3008

11. Ribeiro MAC, Freitas JM, Muňoz RAA, Do Lagob CL, Richter EM (2016) Fast determination of diphenhydramine, pyridoxine, and 8-chlorotheophylline by capillary electrophoresis with capacitively coupled contactless conductivity detection. Anal Methods 8:4432-4437

12. Simpson K, Jarvis B (2000) Fexofenadine: a review of its use in the management of seasonal allergic rhinitis and chronic idiopathic urticaria. Drugs 59:301-321

13. Meeves SG, Appajosyula S (2003) Efficacy and safety profile of fexofenadine $\mathrm{HCl}$ A unique therapeutic option in $\mathrm{H} 1$-receptor antagonist treatment. J Allergy Clin Immunol 112:S69-S77

14. Sharma K, Bhatia R, Anghore D, Singh V, Khare R, Rawal RK (2018) Development and validation of UV-spectrophotometric and RPHPLC methods for simultaneous estimation of fexofenadine hydrochloride, montelukast sodium and ambroxol hydrochloride in tablet dosage form. Anal Chem Lett 8:829-843

15. Helmy SA, El Bedaiwy HM (2016) HPLC determination of fexofenadine in human plasma for therapeutic drug monitoring and pharmacokinetic studies. Biomed Chromatogr 30:1059-1064

16. dos Antônio M, Júnior R, Miranda de Faria AC, Eudes SV, Teresa DC, Frank PA, Whocely VC (2015) Determination of fexofenadine in hank's balanced salt solution by high-performance liquid chromatography with ultraviolet detection: application to caco-2 cell permeability studies. Biomed Chromatogr 29:537-544

17. Vekaria H, Limbasiya V, Patel P (2013) Development and validation of RP-HPLC method for simultaneous estimation of montelukast sodium and fexofenadine hydrochloride in combined dosage form. J Pharm Res 6:134-139

18. Arayne MS, Sultana N, Shehnaz H, Haider A (2011) RP-HPLC method for the quantitative determination of fexofenadine hydrochloride in coated tablets and human serum. Med Chem Res 20:55-61

19. Arayne MS, Sultana N, Mirza AZ, Siddiqui FA (2010) Simultaneous determination of gliquidone, fexofenadine, buclizine, and levocetirizine in dosage formulation and human serum by RPHPLC. J Chromatogr Sci 48:382-385

20. Ashour S, Khateeb M, Mahrouseh R (2013) Extractive spectrophotometric and conductometric methods for determination of fexofenadine hydrochloride in pharmaceutical dosage forms. Pharm Anal Acta S2:1-6

21. Polawar PV, Shivhare UD, Bhusari KP, Mathur VB (2008) Development and validation of spectrophotometric method of analysis for fexofenadine. Res J Pharm Technol 1:539-541

22. Maggio RM, Castellano PM, Vignaduzzo SE, Kaufman TS (2007) Alternative and improved method for the simultaneous determination of fexofenadine and pseudoephedrine in their combined tablet formulation. J Pharm Biomed Anal 45:804-810

23. Kumar KS, Ravichandran V, Mohan MK, Thyagu R, Dharamsi A (2006) Spectrophotometric determination of fexofenadine hydrochloride. Indian J Pharm Sci 68:841-842

24. Gowda BG, Melwanki MB, Seetharamappa J (2001) Extractive spectrophotometric determination of ceterizine $\mathrm{HCl}$ in pharmaceutical preparations. J Pharm Biomed Anal 25:1021-1026

25. Alothman ZA, Bukhari N, Haider S, Wabaidur SM, Alwarthan AA (2010) Spectrofluorimetric determination of fexofenadine hydrochloride in pharmaceutical preparation using silver nanoparticles. Arab J Chem 3:251-255

26. Abbas MN, Fattah AA, Zahran E (2004) A novel membrane sensor for histamine $\mathrm{H} 1$-receptor antagonist fexofenadine. Anal Sci 20:1137-1142

27. Breier AR, Garcia SS, Jablonski A, Steppe M, Schapoval EES (2005) Capillary electrophoresis method for fexofenadine hydrochloride in capsules. J AOAC Int 88:1059-1063

28. Slater JW, Zechnich AD, Haxby DG (1999) Second-generation antihistamines. Drugs 57:31-47

29. Suryan AL, Bhusari VK, Rasal KS, Dhaneshwar SR (2011) Simultaneous quantitation and validation of paracetamol, phenylpropanolamine hydrochloride and cetirizine hydrochloride by RP-HPLC in bulk drug and formulation. Int J Pharm Sci Drug Res 3:303-308

30. Dharuman J, Vasudhevan M, Ajithlal T (2011) High performance liquid chromatographic method for the determination of cetirizine and ambroxol in human plasma and urine-a boxcar approach. J Chromatogr B Anal Technol Biomed Life Sci 879:2624-2631

31. Sharaf El-Din MK, Ibrahim F, Wahba MEK (2013) Chemometrically optimized micellar liquid chromatographic method for the simultaneous determination of cetirizine dihydrochloride in its combined dosage forms. Application to biological fluids and pharmacokinetic studies. Acta Chromatographia 25:59-77

32. Katselou M, Athanaselis S, Nikolaou P, Dona A, Spiliopoulou C, Papoutsis I (2017) Development and validation of a GC-MS method for the determination of hydroxyzine and its active metabolite, cetirizine, in whole blood. J Pharm Biomed Anal 145:765-772

33. Javid FS, Shafaat A, Zarghi A (2014) Determination of cetirizine and its impurities in bulk and tablet formulation using a validated capillary zone electrophoretic method. J Anal Chem 69:442-447

34. Azhagvuel S, Sekar R (2007) Method development and validation for the simultaneous determination of cetirizine dihydrochloride, paracetamol, and phenylpropanolamine hydrochloride in tablets by capillary zone electrophoresis. J Pharm Biomed Anal 43:873-878 
35. Karakaya S, Dilgin DG (2019) Low-cost determination of cetirizine by square wave voltammetry in a disposable electrode. Monatsh für Chem 150:1003-1010

36. Kalambate PK, Srivastava AK (2016) Simultaneous voltammetric determination of paracetamol, cetirizine and phenylephrine using a multiwalled carbon nanotube-platinum nanoparticles nanocomposite modified carbon paste electrode. Sens Actuators B 233:237-248

37. Rizk NMH, Abbas SS, El-Sayed FA, Abo-Bakr A (2009) Novel ionophore for the potentiometric determination of cetirizine hydrochloride in pharmaceutical formulations and human urine. Int $J$ Electrochem Sci 4:396-406

38. Souha HY, Maha AH, Dalia M, Amr MB (2018) Analysis of paracetamol, pseudoephedrine and cetirizine in Allercet Cold capsules using spectrophotometric techniques. Chem Cent J 67:1-14

39. (2005) International conference on harmonization of technical requirements for registration of pharmaceuticals for human use; ICH harmonized tripartite guideline, Validation of analytical procedures: text and methodology, Q2(R 1) (1996), Complementary guideline on methodology dated $06 \mathrm{Nov}$. ICH, London

40. Miller JC, Miller JN (2005) Statistics and chemometrics for analytical chemistry, 5th edn. Prentice Hall, England
41. Job P (1928) Formation and stability of inorganic complexes in solution. Ann Chem (France) 9:113-203

42. Yoe JH, Jones AL (1944) Colorimetric determination of iron with disodium-1,2-dihydroxybenzene-3,5-disulfonate. Ind Eng Chem Anal Ed 16:111-115

43. Foster R (1969) Organic charge-transfer complexes. Academic Press, London, pp 51-87

44. Vogel's (1989) Text-book of practical organic chemistry, 5th edn. Longman Group UK Ltd, England, pp 1442-1444

45. Vosburgh WC, Cooper GR (1941) Complex ions. I. The identification of complex ions in solution by spectrophotometric measurements. J Am Chem Soc 63:437-442

46. (1994) International conference on harmonization I. Validation of analytical procedures: text and methodology, Q2(R1). Geneva, Switzerland

Publisher's Note Springer Nature remains neutral with regard to jurisdictional claims in published maps and institutional affiliations. 